\title{
Role and regulation of interleukin-1 molecules in pro-asthmatic sensitised airway smooth muscle
}

\author{
R. Whelan, C. Kim, M. Chen, J. Leiter, M.M. Grunstein, H. Hakonarson
}

\begin{abstract}
Role and regulation of interleukin-1 molecules in pro-asthmatic sensitised airway smooth muscle. R. Whelan, C. Kim, M. Chen, J. Leiter, M. M. Grunstein, H. Hakonarson. (C) ERS Journals Ltd 2004.

ABSTRACT: Interleukin (IL)-1ß is a pleiotropic, pro-inflammatory cytokine that has been importantly implicated in driving the inflammatory response and resultant changes in airway smooth muscle (ASM) responsiveness in asthma. IL-1 $\beta$ belongs to a family of molecules, known as the IL-1 axis, which exert both pro- and anti-inflammatory effects. Since dysregulation of IL-1 axis molecules may be critical in the pathobiology of asthma, the present study examined the expression and activation of both the inhibitory and stimulatory IL-1 axis molecules in human ASM cells and their roles in modulating cytokine and immunoglobulin (Ig)E immune complex (IgE cx)-mediated changes in rabbit ASM constrictor and relaxant responsiveness.

The results demonstrate the following. 1) Pre-treatment of isolated rabbit tracheal rings with the inhibitory IL-1 axis members, IL-1 receptor antagonist and IL-1 type-II receptor abrogated both IL-5- and IgE cx-induced changes in ASM responsiveness. 2) Administration of IL-5, IL-1 $\beta$ and IgE cxs to human ASM cells increased mRNA and protein expressions of both stimulatory and inhibitory IL-1 axis molecules. 3) The time course of IL-5-induced IL-1 axis molecule expression preceded that of both IL-1ß and IgE immune cxs.

Collectively, these findings suggest that modulation at the level of the interleukin-1 axis of molecules may have significant therapeutic potential in the treatment of asthma. Eur Respir J 2004; 24: 559-567.
\end{abstract}

Division of Pulmonary Medicine, The Joseph Stokes Jr Research Institute, The Children's Hospital of Philadelphia, University of Pennsylvania School of Medicine, Philadelphia, PA, USA.

Correspondence: H. Hakonarson, Division of Pulmonary Medicine, The Children's Hospital of Philadelphia, University of Pennsylvania School of Medicine, 34th Street and Civic Center Boulevard, Philadelphia, PA 19104, USA.

Fax: 12155901397

E-mail: hakonarson@email.chop.edu

Keywords: Airway hyperresponsiveness, airway smooth muscle, interleukin-1 axis, interleukin-5

Received: December 32003

Accepted after revision: June 82004

This work was supported by the National Heart Lung and Blood Institute Grant, HL59906.
Airway inflammation together with enhanced agonistmediated bronchoconstriction and impaired adrenoceptormediated airway relaxation are characteristic features of bronchial asthma [1, 2]. While the mechanisms underlying these inflammation-associated changes in airway responsiveness remain to be elucidated, substantial recent evidence has implicated a crucial role for CD4+ T-helper (Th) type-2 cytokines in the pathophysiology of the inflammatory response and its accompanying changes in airway responsiveness in asthma. In this regard, the Th2 cytokines, interleukin (IL)-4, IL-13 and IL-5, are known to orchestrate various humoral and cellular immune responses that are characteristic of allergic asthma, including immunoglobulin (Ig)E synthesis, eosinophil recruitment and activation [3-5]. These cytokines have also been shown to modulate airway responsiveness by direct action on the airway smooth muscle (ASM) itself [6-8].

While Th2 cytokines are known to play a critical role in the pathophysiology of asthma, recent evidence suggests that the altered airway response in asthma may be triggered by the action of IgE immune complexes (IgE cxs) on the ASM. Indeed, administration of IgE cxs to ASM has been shown to initiate a signalling cascade that results in the induced expression and autocrine action of IL-5, which, in turn, triggers the production of the pleiotropic, pro-inflammatory cytokine IL$1 \beta$ [9]. IL- $1 \beta$ is a pivotal cytokine that is centrally involved in both local and systemic immune responses. There is evidence that dysregulated synthesis and prolonged release of IL-1 $\beta$ in chronic inflammatory conditions, such as inflammatory bowel disease, psoriasis and rheumatoid arthritis, may contribute to the pathogenesis of these diseases [10]. Moreover, IL-1 $\beta$ has also been implicated in the early phase of both the inflammatory response and altered airway responsiveness of an asthma patient, and elevated levels of IL-1 $\beta$ protein have been shown to be present in the airways of patients with asthma $[11,12]$. Furthermore, there is cumulative evidence showing that IL-1 $\beta$ modulates airway constrictor and relaxation responses by direct action on the ASM itself [6, 8]. Taken together, this evidence highlights the important role of IL-1 $\beta$ in the pathophysiology of asthma.

The IL-1 type-I (IL-1RI) and type-2 (IL-1RII) receptor molecules are two distinct receptors that bind to both IL- $1 \alpha$ and IL-1 $\beta$ [13]. The IL-1RI receptor is responsible for producing the biological effects that are attributed to IL-1 signalling $[14,15]$. In contrast, the IL-1RII receptor does not possess a functional cytoplasmic signalling peptide, and, thus, serves as a decoy receptor that binds to IL-1 and attenuates IL-1 signalling [16]. In addition, the IL-1RII receptor can be cleaved into a soluble form (sIL-1RII), which binds to IL-1 $\beta$ with high affinity, further reducing the amount of available IL-1 $\beta$ [17]. Accordingly, IL-1RII is capable of dampening the IL-1 pathway by sequestering IL-1. The IL-1 receptor antagonist (IL-1ra) is another mechanism by which IL-1 activity can be inhibited. IL-1ra has been shown to bind to IL-1RI with an affinity approximating IL- $1 \alpha$ and IL-1 $\beta$, but does not induce signal transduction [18]. IL-1 ra pre-treatment has also been shown to significantly reduce IL-1-mediated inflammatory damage in various experimental models, suggesting that these anti-inflammatory effects are receptor specific [19, 20]. Although the IL-1 axis molecules, IL-RL1 
(also known as T1/ST2) and IL-18RI, are not directly involved in IL-1 signalling, both are important markers of inflammation. Increased levels of IL-1RL1 are present in the sera of asthma patients following an acute exacerbation [21] and IL-18 signalling is also notably upregulated. Thus, IL-1RL1 and IL-18RI serve as markers of IL-1-mediated inflammation in asthma.

While numerous studies have addressed the role of IL- $1 \beta$ in inflammatory conditions such as asthma, there has been little attention given to the other members of the IL-1 axis molecules. Accordingly, the present study examined whether the IL-1 family of molecules are differentially regulated in pro-asthmatic-sensitised airways either at baseline or in response to inflammatory mediators, such as IgE cxs, IL-5 and IL-1 $\beta$, which have been importantly implicated in the development of the pro-asthmatic state.

\section{Materials and methods}

Preparation of airway smooth muscle tissue, incubation with IL-5, IgE complexes and members of the IL-1 family of molecules

A total of 14 New Zealand white adult rabbits were used in this study, which was approved by the Biosafety, Animal Research and the Institutional Review Board (IRB) Committees of the Joseph Stokes Research Institute at Children's Hospital of Philadelphia, PA, USA. The animals had no signs of respiratory disease for several weeks before the study. The human ASM cells were purchased from Clonetics (San Diego, CA, USA) and their use was similarly approved by the IRB Committees.

IgE csx, IL-1 $\beta$ and IL-5 were separately administered to isolated rabbit ASM tissue in the absence and presence of the inhibitory IL-1 family members, IL-1ra and sIL-1RII, and changes in the tissues' agonist-mediated constrictor and relaxation responsiveness were examined. In brief, after anaesthesia with xylazine $\left(10 \mathrm{mg} \cdot \mathrm{kg}^{-1}\right)$ and ketamine $\left(50 \mathrm{mg} \cdot \mathrm{kg}^{-1}\right)$, rabbits were sacrificed, their tracheae removed via open thoracotomy, cleared of loose connective tissue and epithelium, and divided into eight ring segments of $6-8 \mathrm{~mm}$ length. Each alternative smooth muscle ring was incubated for $24 \mathrm{~h}$ at room temperature in either: Dulbecco's Modified Eagles Medium (DMEM) alone, or DMEM in the presence of either IL-5 (4 $\mathrm{ng} \cdot \mathrm{mL}^{-1}$; R\&D Systems, Minneapolis, MN, USA), IL-1 $\beta$ $\left(5 \mathrm{ng} \cdot \mathrm{mL}^{-1}\right)$ or IgE cxs, with and without 1 -h pre-treatment of either sIL-1RII $\left(5 \mu \mathrm{g} \cdot \mathrm{mL}^{-1}\right.$; R\&D Systems) or IL-1ra (140 $\mathrm{ng} \cdot \mathrm{mL}^{-1} ; \mathrm{R} \& \mathrm{D}$ Systems). The concentration of the IgE cxs used was $15 \mu \mathrm{g} \cdot \mathrm{mL}^{-1}$ of human $\mathrm{IgE}$ and $5 \mu \mathrm{g} \cdot \mathrm{mL}^{-1}$ goat anti-human IgE (Biodesign International, Saco, ME. USA). The incubation media were aerated with a continuous supplemental $95 \% \quad \mathrm{O}_{2} / \mathrm{CO}_{2}$ mixture during the incubation phase. The concentrations of IgE, IL5 and IgE cxs were the maximum effective concentrations of these molecules, as previously described $[6,7,9,22,23]$.

\section{Pharmacodynamic studies}

Following incubation, each tissue segment was suspended longitudinally between stainless steel triangular supports in siliconised Harvard 20-mL organ baths (Harvard Apparatus, South Natick, MA, USA). The lower support was secured to the base of the organ bath and the upper support was attached via a gold chain to a Grass FT.03C force transducer (Grass Instruments, Quincy, MA, USA), from which isometric tension was continuously displayed on a multichannel recorder. The tissues were bathed in modified Krebs-Ringer solution. The baths were aerated with $5 \% \mathrm{CO}_{2}$ in $\mathrm{O}_{2}$; a $\mathrm{pH}$ of 7.35-7.40 was maintained and the organ bath temperature was held at $37^{\circ} \mathrm{C}$. Cholinergic contractility was assessed by cumulative administration of acetycholine (ACh; $10^{-10}$ $\left.10^{-3} \mathrm{M}\right)$. Thereafter, in separate studies, relaxation doseresponse curves to isoproterenol $\left(10^{-10}-10^{-4} \mathrm{M}\right)$ were conducted in tissues half-maximally contracted with ACh. The relaxant responses to isoproterenol were analysed in terms of per cent maximal relaxation ( $\mathrm{Rmax}$ ) from the active cholinergic contraction, and sensitivity to the relaxing agent was determined as the negative logarithm of the dose of the relaxing agent producing $50 \%$ of $\mathrm{R} \max (\mathrm{pD} 50$; i.e. geometric mean dose of drug which produces $50 \%$ of its maximum response (ED50) value).

Preparation and treatment of cultured airway smooth muscle cells

Human ASM (HASM) cells were derived from male donors aged 16 and 21 yrs (Clonetics), who had no evidence of pulmonary disease, and the cells were cultured at $37^{\circ} \mathrm{C}$ in a humidified atmosphere of $5 \% \mathrm{CO}_{2}$ and $95 \%$ air. The cells used in this study were at passage 5-7 and were grown to $95 \%$ confluency in smooth muscle basal medium (SmBM), which was supplemented with $10 \%$ foetal bovine serum insulin $\left(5 \mathrm{ng} \cdot \mathrm{mL}^{-1}\right)$, epidermal growth factor $\left(10 \mathrm{ng} \cdot \mathrm{mL}^{-1}\right.$; human recombinant), fibroblast growth factor $\left(2 \mathrm{ng} \cdot \mathrm{mL}^{-1}\right.$; human recombinant) and gentamycin $\left(50 \mathrm{ng} \cdot \mathrm{mL}^{-1}\right)$, as previously described $[6,7,9]$. After growing the cells to confluence, the cells were starved in unsupplemented SmBM (SFM), and then exposed, for varying durations, to either serum-free media alone (control), IgE cxs $\left(15 \mu \mathrm{g} \cdot \mathrm{mL}^{-1}\right.$ human IgE, $5 \mu \mathrm{g} \cdot \mathrm{mL}^{-1}$ goat anti-human IgE), IL-5 (4 $\left.\mathrm{ng} \cdot \mathrm{mL}^{-1}\right)$ or IL-1 $\beta\left(1 \mathrm{ng} \cdot \mathrm{mL}^{-1}\right)$. The cell media were salvaged and the cells were washed three times in PBS buffer, and used for the various RNA and protein experiments. All experiments were performed in triplicate.

\section{Determination of $I L-1$ axis $m R N A$ expression}

To analyse mRNA expression of the human IL-1 axis members IL-1 $\alpha$, IL-1 $\beta$, IL-1 $\beta$ converting enzyme (ICE; caspase-1), IL-1ra, sIL-1RI, sIL-1RII, IL-1RL1, IL-1 receptor accessory protein (IL-1RacP) and IL-18RI, RT-PCR was used and human-specific primers were used, based on the published sequences of these human genes and included the following primer sets. For ICE: 5'-primer 5'-GTGCAGGACAACCCAGCTAT-3', 3'-primer 5'-CGCTGTACCCCAGATTTTGT-3' (product is $250 \mathrm{bp}$ ); for IL-1RI: 5'-primer 5'-ATCGTGATGAATGTGGCTGA-3', 3'-primer 5'-TGACCCATTCCACTTCCAGT-3' (product is $252 \mathrm{bp}$ ); for IL- $1 \alpha$ : 5'-primer 5'-CGGGAAGGTTCTGAAGAAGA-3', 3'-primer 5'-AGCAGCCGTGAGGTACTGAT-3' (product is $235 \mathrm{bp}$ ); for IL-1 $\beta$ : 5' -primer 5'-GGACAAGCTGAGGAAGATGC-3', 3'-primer 5'-TCCATATCCTGTCCCTGGAG-3' (product is $246 \mathrm{bp}$ ); for IL-1RL1: $5^{\prime}$-primer 5'-TGGATATGCGAATGTCACCA-3', 3'-primer 5'-GGTGTAATCACCTGCGTCCT-3' (product is $250 \mathrm{bp}$ ); for IL-1RAcP: 5'-primer 5'-TCTGATGGATTCTCGCAATG-3', $3^{\prime}$-primer 5'-TCTTGGAGCTGGCACTTTCT-3' (product is $253 \mathrm{bp}$ ); for IL-18RI: 5'-primer 5'-CTGCTCTGCTTTGCTGAATG-3', 3'-primer 5'-AGCCATGTCTGCTTTTCTCA-3' (product is $250 \mathrm{bp}$ ); for IL-1ra: 5'-primer 5'-GGAATCCATGGAGGGAAGAT-3', 3'-primer 5'-CCTTCGTCAGGCATATTGGT-3' (product is $245 \mathrm{bp}$ ); for IL-1RII: 
5'-primer 5'-TGGCACCTACGTCTGCACTA-3', 3'-primer 5'-TGGTCCCCCTCACACTTAGA-3' (product is $260 \mathrm{bp}$ ); for RPL7: 5'-primer 5'-AAGAGGCTCTCATTTTCCTGGCTG-3', 3'-primer 5'-TCCGTTCCTCCCCATAATGTTCC$3^{\prime}$ (product is $157 \mathrm{bp}$ ).

The experimental values of ribosomal protein L7 (RPL7) were used as loading controls. The cycling profile used was as follows: denaturation at $95^{\circ} \mathrm{C}$ for $1 \mathrm{~min}$; annealing at $52-60^{\circ} \mathrm{C}$ for $1 \mathrm{~min}$; and extension at $72^{\circ} \mathrm{C}$ for $1 \mathrm{~min}$. The cycles used were: $31-34$ cycles for the IL-1 axis genes; and 26 cycles for the RPL7 gene. The PCR reactions for the individual products were performed using equivalent amounts of complementary DNA (cDNA) prepared from $2.5 \mu \mathrm{g}$ of total RNA, and equal aliquots of each PCR reaction were then run on a $1.2 \%$ agarose gel and each gene's DNA levels were assayed by Southern blot analysis using product-specific $32^{\mathrm{P}}$-labelled probes. Southern blots were quantitated by direct measurements of radioactivity in each band using a PhosphoImager (Molecular Dynamics, Boston, MA, USA).

Determination of IL-1 axis protein expression by Western blot analysis

Protein expression of the IL-1 axis members IL-1RI, IL1RAcP, IL-1ra and IL-1RII were assayed by Western blot analysis of membrane protein lysate samples isolated from cultured human ASM cells following 0-, 24-, and 48-h treatments with either SFM alone, or SFM containing either IL-5 $\left(4 \mathrm{ng} \cdot \mathrm{mL}^{-1}\right)$, IL-1 $\beta\left(1 \mathrm{ng} \cdot \mathrm{mL}^{-1}\right)$ or IgE cxs $\left(15 \mu \mathrm{g} \cdot \mathrm{mL}^{-1}\right.$ human IgE, $5 \mu \mathrm{g} \cdot \mathrm{mL}^{-1}$ goat anti-human IgE). The protein lysate samples were homogenised and prepared in 40 volumes of $50 \mathrm{mM}$ Tris- $\mathrm{HCl}, 150 \mathrm{mM} \mathrm{NaCl}, 1 \mathrm{mM}$ EDTA (pH 7.4) containing $1 \mathrm{mM}$ phenylmethylsulfonyl fluoride, $5 \mu \mathrm{g} \cdot \mathrm{mL}^{-1}$ aprotinin and $5 \mu \mathrm{g} \cdot \mathrm{mL}^{-1}$ leupeptin. Nuclei and large particulates were removed by centrifugation at $100 \times g$ for $5 \mathrm{~min}$. The supernatant was then recovered and the protein concentration was measured using the Lowry assay. Equivalent amounts $(30-50 \mu \mathrm{g})$ of cellular protein were fractionated in 9-11\% SDS-polyacrylamide gels, followed by transfer to nitrocellulose membranes. The membranes were then blotted with the primary antibodies overnight at $4{ }^{\circ} \mathrm{C}$ in $25 \mathrm{mM}$ Tris- $\mathrm{HCl}$ (pH 7.5), $150 \mathrm{mM} \mathrm{NaCl}$ and $0.5 \%$ Triton$\mathrm{X}-100$ containing $5 \%$ non-fat milk, as described previously [22]. All primary antibodies used were mouse anti-human monoclonal antibodies (R\&D Systems) in a 1:250 dilution. The IL-1 axis protein levels were detected using enhanced chemiluminescence after 1 -h incubation with a 1:1,000 dilution of an anti-mouse horseradish peroxidase-linked secondary antibody in $25 \mathrm{mM}$ Tris- $\mathrm{HCl}(\mathrm{pH} \mathrm{7.5),} 150 \mathrm{mM}$ $\mathrm{NaCl}$ and $0.05 \%$ Triton-X-100 containing $0.50 \%$ non-fat milk, and subsequent exposure to autoradiography film.

\section{ELISA measurements of IL-1ra and SIL-1 RII proteins}

Protein levels of IL-1ra and sIL-1RII were measured in the culture media of ASM cells that were exposed for both 0 and $24 \mathrm{~h}$ to either treatment with SFM alone or with SFM containing either IL-5 $\left(4 \mathrm{ng} \cdot \mathrm{mL}^{-1}\right)$ or IL-1 $\beta\left(1 \mathrm{ng} \cdot \mathrm{mL}^{-1}\right)$. The IL-1ra and sIL-1RII protein levels were quantitatively assessed using an enzyme-specific immunoassay, as previously described [6]. The latter assay was performed using a doubleantibody sandwich strategy in which an acetylcholine-esterase (AChE), Fab-conjugated IL-1ra- or sIL-1RII-specific secondary antibody is targeted to a first cytokine-captured antibody (R\&D Systems). The enzymatic activity of the AChE was measured spectrophotometrically, and, relative to a linear standard curve (range $0-250 \mathrm{pg} \cdot \mathrm{mL}^{-1}$ ), the results were used to quantify the amount of the targeted IL-1ra and sIL-1RII present in the cell culture media. In addition, HASM cells were also exposed to IgE immune cxs $\left(15 \mu \mathrm{g} \cdot \mathrm{mL}^{-1}\right.$ human $\mathrm{IgE}, 5 \mu \mathrm{g} \cdot \mathrm{mL}^{-1}$ goat anti-human IgE) for 0 and $24 \mathrm{~h}$ in the absence and presence of $1 \mathrm{~h}$ pre-treatment with a maximum effective concentration $\left(50 \mathrm{ng} \cdot \mathrm{mL}^{-1}\right)$ of an IL-5 receptor neutralising antibody (IL-5ra; R\&D Systems).

\section{Statistical analyses}

Statistical analyses were performed using the two-tailed paired t-test and ANOVA with multiple comparison of means, where appropriate. Statistical p-values $<0.05$ were considered significant.

\section{Results}

Role of IL-1 axis molecules in regulating agonistmediated responsiveness in cytokine-and $\operatorname{IgE}$ immune complex-sensitised rabbit airway smooth muscle

To examine the modulatory effects of the inhibitory IL-1 axis members, IL-1ra and sIL-1RII, on IL-5-induced changes in airway responsiveness, agonist mediated ASM constrictor and relaxant responses were separately compared in IL-5treated pairs of rabbit ASM segments in the absence and presence of sIL-1RII or IL-1ra. As shown in figure 1, relative to media-treated (control) tissues, the constrictor responses to exogenously administered ACh were significantly increased in the IL-5-treated ASM. Accordingly, the maximum tension (Tmax) values (mean \pm SEM) amounted to $81.32 \pm 5.43$ and $99.97 \pm 6.36 \mathrm{~g} \cdot \mathrm{g}$ ASM weight ${ }^{-1}$ with corresponding ED50 values of $5.16 \pm 0.11$ and $5.26 \pm 0.11-\log \mathrm{M}$ in the control and IL-5 sensitised tissues, respectively $(\mathrm{p}<0.005)$, representing an average increase in Tmax of $22.9 \%$ above the control value in the IL-5-treated ASM. Moreover, the enhanced constrictor response to $\mathrm{ACh}$, in the IL-5-treated tissues, was largely abrogated in tissues that were pre-treated with sIL1RII (fig. 1a) or IL-1ra (fig. 1b). In contrast, the constrictor responses to ACh were unaltered in the control ASM tissues that were treated with either IL-1ra or sIL-1RII (data not shown).

In extended studies, during comparable levels of initial sustained ACh-induced contractions, averaging $\sim 50 \%$ of Tmax in control and IL-5-sensitised rabbit ASM segments, administration of the $\beta$-adrenoceptor agonist, isoproterenol, produced cumulative dose-dependent relaxation of the precontracted tissues. As depicted in figure 2, relative to control ASM, Rmax responses and pD50 values to isoproterenol were significantly attenuated in the IL-5 sensitised tissues. Accordingly, the Rmax values (mean \pm SEM) in the IL- 5 sensitised and control ASM amounted to $55.68 \pm 3.03$ and $47.83 \pm 4.12 \%$, respectively $(\mathrm{p}<0.01)$. The corresponding $\mathrm{pD} 50$ values for isoproterenol averaged $6.39 \pm 0.03$ and $6.38 \pm 0.03-\log \mathrm{M}$, respectively. Moreover, the impaired $\mathrm{Rmax}$ response to isoproterenol was largely prevented in IL-5-sensitised tissues that were pre-treated with either sIL-RII (fig. 2a) or IL-1 ra (fig. 2b). In comparable experiments, neither sIL-1RII nor IL$1 \mathrm{ra}$ was found to significantly affect the ASM relaxation responses to isoproterenol in control tissues (data not shown).

Comparable experiments to those described previously for IL-5 were also performed to determine the effects of IgE immune cxs on rabbit ASM constrictor and relaxant 

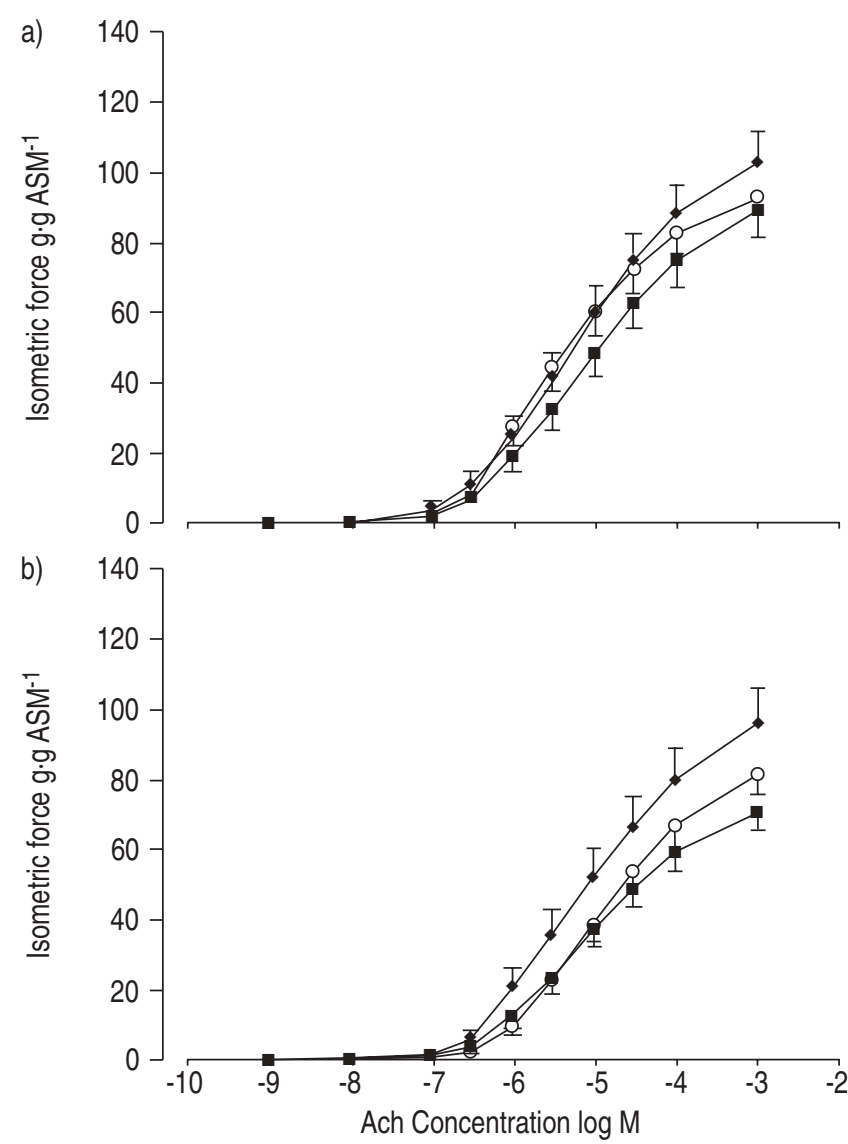

Fig. 1.- Interleukin (IL)-5-induced changes in rabbit airway smooth muscle (ASM) constrictor responsiveness. Comparison of constrictor dose-response relationships to acetylcholine $(\mathrm{ACh})$ in control $(\mathbf{\square})$, and IL-5-treated rabbit ASM tissues in the absence $(\bullet)$ and presence $(\bigcirc)$ of either a) soluble IL-1 type-II receptor (sIL-1RII) or b) IL-1 receptor antagonist (IL-1ra). Data are presented as mean \pm SEM values. The maximum tension $\left(\mathrm{T}_{\max }\right)$ values to $\mathrm{ACh}$ are significantly enhanced in tissues treated with IL-5, and these effects of IL-5 are largely ablated in the presence of either sIL-1RII or IL-1ra. Experiments were performed in triplicate.

responsiveness, both in the absence and presence of IL-1ra or sIL-1RII, respectively. Accordingly, the Tmax values (mean \pm SEM) amounted to $83.56 \pm 6.22$ and $104.84 \pm 7.16 \mathrm{~g} \cdot \mathrm{g} \mathrm{ASM}$ weight ${ }^{-1}$ with corresponding ED50 values of $5.19 \pm 0.09$ and $5.30 \pm 0.10-$ $\log \mathrm{M}$ in the control and $\mathrm{IgE}$ immune cx-sensitised tissues, respectively $(\mathrm{p}<0.01)$. Moreover, the enhanced Tmax and ED50 values to $\mathrm{ACh}$ in the $\mathrm{IgE}$ immune cx-treated tissues were largely abrogated in tissues that were pre-treated with sIL-1RII ( $86.67 \pm 7.54$ and $5.22 \pm 0.10$, respectively) or IL-1 ra (87.12 \pm 6.84 and 5.21 \pm 0.11 , respectively). Similarly, the Rmax responses and $\mathrm{pD} 50$ values to isoproterenol were significantly attenuated in the IgE immune cx-sensitised tissues. Accordingly, the $R \max$ values (mean \pm SEM) in the $\mathrm{IgE}$ immune cx-treated and control ASM amounted to $57.22 \pm 5.12$ and $45.23 \pm 5.32 \%$, respectively $(\mathrm{p}<0.01)$. The corresponding $\mathrm{pD} 50$ values for isoproterenol averaged $6.34 \pm 0.05$ and $6.36 \pm 0.05-$ $\log \mathrm{M}$, respectively. Moreover, the impaired Rmax response to isoproterenol was ablated in IgE immune cx-sensitised tissues that were pre-treated with either sIL-RII $(54.32 \pm 6.10)$ or IL1 ra (55.87 \pm 5.89$)$. Similar effects on ASM contractility and relaxation to those observed with IL-5 and IgE immune cxs were also observed in rabbit ASM tissues that were exposed to IL-1 $\beta$, and these effects of IL- $1 \beta$ were abrogated with either IL-1ra or sIL-1RII (data not shown).
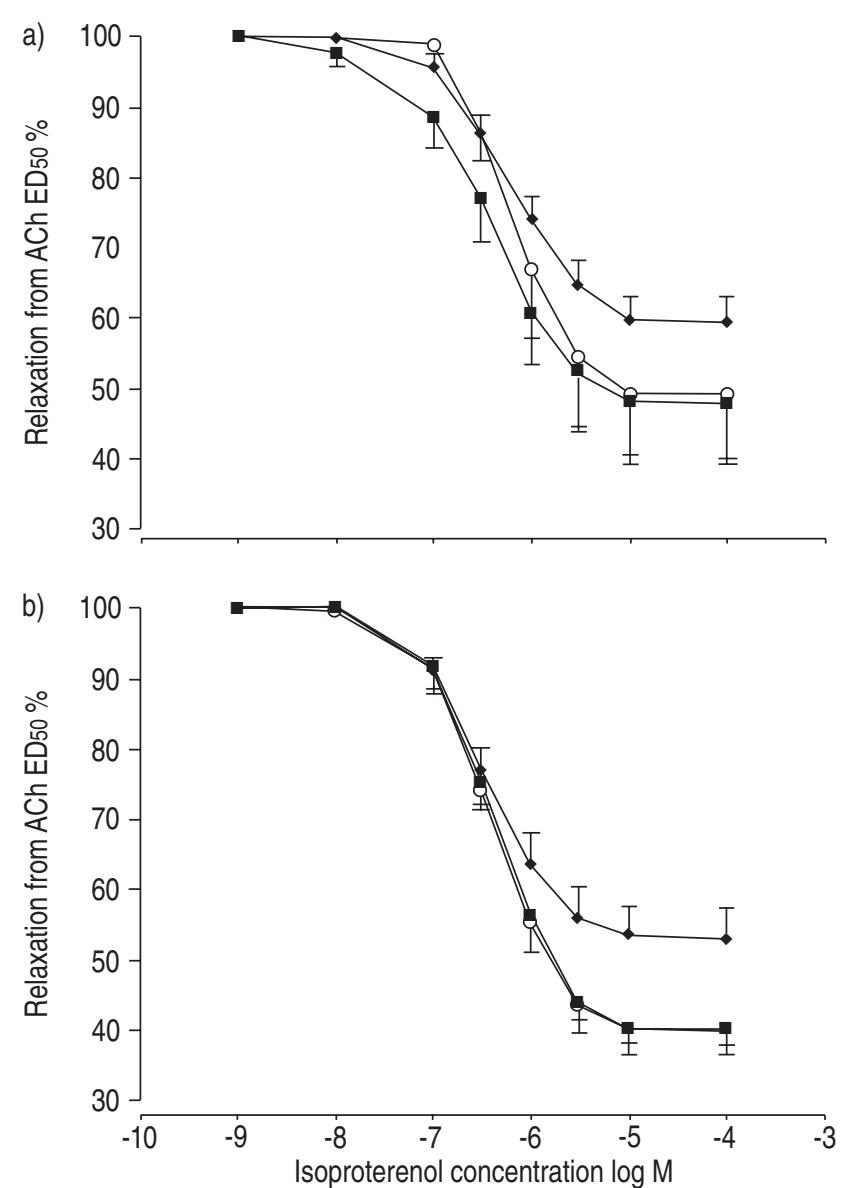

Fig. 2. - Interleukin (IL)-5-induced changes in rabbit airway smooth muscle (ASM) relaxant responsiveness. Comparison of relaxation response curves to isoproterenol in control (ם), and IL-5 treated rabbit ASM tissues in the absence $(\diamond)$ and presence $(\bigcirc)$ of either a) soluble IL-1 type-II receptor (sIL-1RII) or b) IL-1 receptor antagonist (IL-1ra). Data are presented as mean \pm SEM values. The attenuated per cent maximum relaxation $\left(R_{\max }\right)$ and the negative logarithm of the dose of the relaxing agent producing $50 \%$ of $\mathrm{R} \max (\mathrm{pD} 50$; i.e. geometric mean dose of drug which produces $50 \%$ of its maximum response (ED50) value) values to isoproterenol in response to IL-5 are ablated in the presence of either sIL-1RII or IL-1ra. Experiments were performed in triplicate. ACh: acetylcholine.

\section{Expression of stimulatory IL-1 axis molecules in human airway smooth muscle}

In light of previous evidence, together with earlier studies showing that exposure of naive ASM to atopic asthmatic serum induces upregulated mRNA expression and release of IL-5, which, in turn, acts in an autocrine manner to induce expression and release of the pro-inflammatory cytokine IL$1 \beta[24,25]$, the present authors next examined whether cultured HASM cells endogenously expresses mRNAs for other stimulatory and inhibitory members of the IL-1 axis molecules, and whether the expression pattern of these molecules is modulated in ASM following administration of IgE cxs, IL-5 or IL-1 $\beta$. Accordingly, Southern blots were prepared and probed with human cDNA probes that were specific for the nucleotide sequences of the IL-1 $\alpha$, IL-1 $\beta$, ICE, IL-1RI and IL-1RacP genes. A 157-bp RPL7 probe was also prepared as a control for gel loading. As shown in figure 3, relative to untreated (control) cells, IL- $1 \alpha$ expression was increased in ASM cells in response to IL-1 $\beta$ alone. Likewise, IL-1 $\beta$ mRNA expression was increased in response to IL-1 $\beta$ 


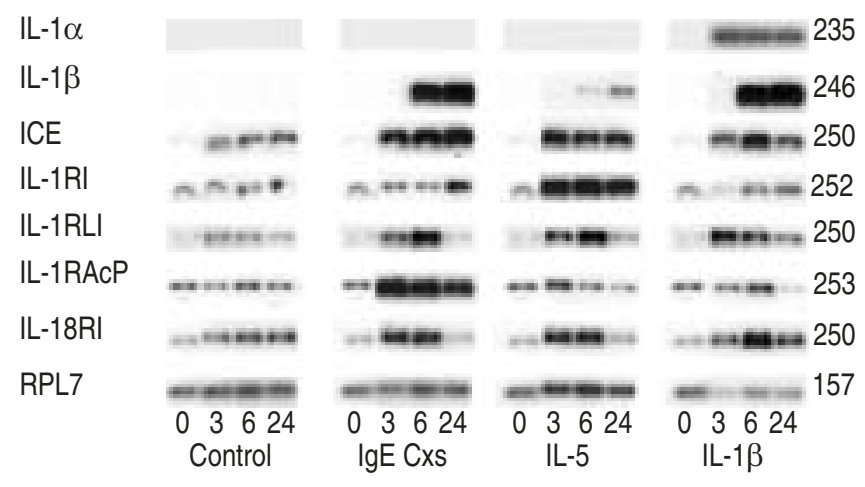

Fig. 3.-mRNA expression of stimulatory interleukin (IL)-1 axis molecules in human airway smooth muscle (HASM). Southern blots of IL$1 \alpha$, IL-1 $\beta$, IL-1 $\beta$ converting enzyme (ICE), IL-1 type-I receptor (IL-1RI), IL-1 receptor-like 1 (IL-RLI), IL-1 receptor accessory protein (RAcP), IL-18 receptor type I (IL-18RI) mRNA expressions in cultured HASM cells after $0,3,6$ and $24 \mathrm{~h}$ of incubation in serum-free medium alone (control) and following treatment with either immunoglobulin ( $\mathrm{Ig}) \mathrm{E}$ immune complexes (IgE cxs), IL-5, or IL-1 $\beta$. Expression of ribosomal protein-L7 (RPL7) was used as a control. Relative to control cells, exposure to IgE cxs, IL-5 or IL-1 $\beta$ resulted in markedly induced expression of these stimulatory IL-1 axis molecules, and the increased levels of expression by IL-5 preceded the induction seen with both IgE cxs and IL-1 $\beta$. Number of base pairs of the cDNA fragment is expressed on the right of the figure. Experiments were performed in triplicate.

itself, and also following 6- and 24-h exposure to either IgE cxs or IL-5. Moreover, relative to control cells, expression of ICE was significantly increased by all treatment conditions (i.e. in response to IgE, IL-5 and IL-1 $\beta$ ) at 3, 6 and $24 \mathrm{~h}$. Interestingly, in contrast to the effects of IL5 and IL-1 $\beta$, both of which increased the expression of IL-1RI at all time points, mRNA expression of the receptor was distinctly increased only at $24 \mathrm{~h}$ in response to IgE cxs. IL-1RAcP expression showed a remarkable increase in response to IgE cxs at all time points measured, whereas there was only a modest increase in IL-1RAcP expression at $3 \mathrm{~h}$ in response to IL-5 and at $6 \mathrm{~h}$ in response to IL-1 $\beta$.

\section{Expression of inhibitory IL-1 axis molecules in human airway smooth muscle}

Apart from the stimulatory group of IL-1 axis molecules, mRNA analyses of the inhibitory IL-1 family members were also performed using Southern blots probed with human cDNA probes specific for the human IL-1ra and sIL-1RII

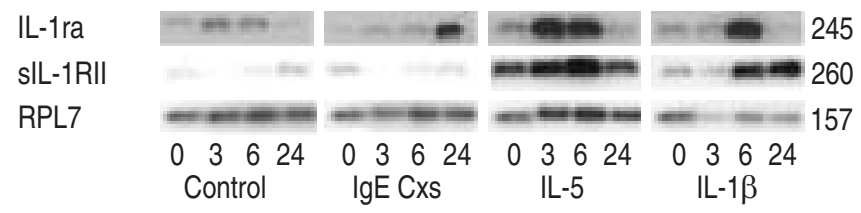

Fig. 4.-mRNA expression of inhibitory interleukin (IL)-1 axis molecules in human airway smooth muscle (HASM). Southern blots of IL-1 receptor antagonist (IL-1ra) and soluble IL-1 type-II receptor (sIL-1RII) mRNA expressions in cultured HASM cells after $0,3,6$ and $24 \mathrm{~h}$ of incubation in serum-free medium alone (control), and following treatment with either immunoglobulin (Ig)E immune complexes (IgE cxs), IL-5 or IL-1 $\beta$. Expression of ribosomal protein-L7 (RPL7) was used as a control. Relative to control cells, exposure to IgE cxs, IL-5 or IL-1 $\beta$ resulted in markedly induced expression of these inhibitory IL-1 axis molecules, and that the increased levels of expression by IL-5 preceded the induction seen with both IgE cxs and IL-1 $\beta$. Number of base pairs of the cDNA fragment is expressed on the right of the figure. Experiments were performed in triplicate. genes. As shown in figure 4, relative to cells exposed to vehicle alone, treatment with IgE cxs produced modest increases in mRNA expression of both IL-1ra and sIL-1RII at $24 \mathrm{~h}$. In contrast, treatment with IL-5 elicited markedly increased mRNA expression of both IL-1ra and sIL-1RII at 3 and $6 \mathrm{~h}$, with a notably attenuated expression at $24 \mathrm{~h}$. Finally, IL-1 $\beta$ treatment resulted in increased expression of IL-1ra at $6 \mathrm{~h}$, and sIL-1RII expression was also increased at $6 \mathrm{~h}$, but remained elevated at $24 \mathrm{~h}$. Collectively, these results suggest that ASM expresses mRNAs for all of the IL-1 axis molecules, and that their mRNA expression is sequentially regulated by IgE cxs, IL-5 and IL-1 $\beta$. IL- 5 resulted in mRNA expression of these molecules prior to both IgE cxs and IL-1 $\beta$, suggesting that IL-5 plays a primary role in the regulation of the IL-1 axis in ASM.

\section{Modulatory effects of $I L-5$ and $I L-1 \beta$ on $I L-1$ axis molecule protein expression in human $A S M$}

In light of the previous observations, together with earlier observations showing that ASM cells are capable of expressing and releasing IL- $1 \beta$ in response to IL-5, IL- $1 \beta$ or IgE cxs $[9,25]$, the current authors investigated the nature of the protein expression and production of other IL-1 family members in HASM cells in response to IL-5 and IL-1 $\beta$. As shown in figure 5, IL-1R1 protein levels detected by Western blot analysis were markedly increased at 6 and $24 \mathrm{~h}$ in response to treatment with IL-5, as well as with IL-1 $\beta$. Similar results were seen with IL-1RAcP, wherein increased protein production was observed up to $24 \mathrm{~h}$ following IL-1 $\beta$ treatment and up to $48 \mathrm{~h}$ in response to IL-5. Comparable increases in protein expression were seen in response to exposure of ASM cells to IgE cxs (data not shown).

Protein determination was also performed on the inhibitory IL-1 family members, notably IL-1ra and IL-1RII. As shown in figure 6, IL-1 ra protein expression was notably increased in response to IL-1 $\beta$ at 6 and 24 h, whereas IL-5 had relatively little effect on the expression of these proteins. When IL-1RII protein expression in response to IL- $1 \beta$ was examined, a band at $\sim 37 \mathrm{kDa}$, corresponding to the soluble isoform of IL-1RII, was detected, with enhanced expression observed at $24 \mathrm{~h}$ in response to both IL-1 $\beta$ and IL-5 (fig. 6). IL-1RII blotting of IL-5-treated ASM cell lysates demonstrated bands at $\sim 68 \mathrm{kDa}$, corresponding to the membrane-bound form of IL-1RII (mIL-1RII). Enhanced expression of mIL-1RII was seen at $6 \mathrm{~h}$ with peak expression occurring at $24 \mathrm{~h}$.

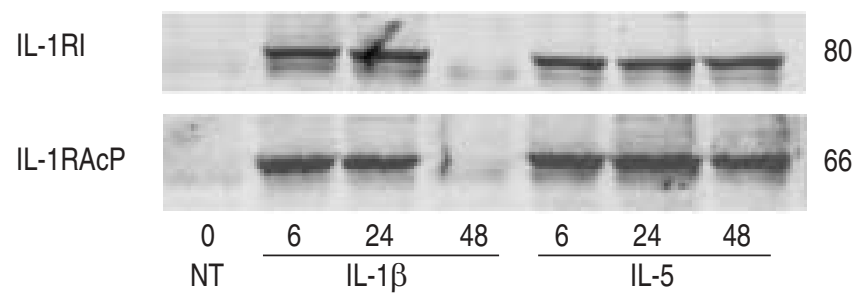

Fig. 5.-Protein expression of stimulatory interleukin (IL)-1 axis molecules in human airway smooth muscle (HASM) cells. Western blots of IL-1 type I receptor (IL-1RI) and IL-1 receptor accessory protein (IL-1 RAcP) expression in cultured HASM cells in serum-free medium (SFM) alone (NT) and following 6, 24 and $48 \mathrm{~h}$ of treatment with either IL-5 or IL-1 $\beta$. Note that relative to SFM, IL-1 $\beta$ and IL-5 treated cells exhibited markedly increased protein levels of both IL-1RI and IL-1RAcP. Number on the right-hand side of the figure is the molecular weight $(\mathrm{kDa})$. Experiments were performed in triplicate. 


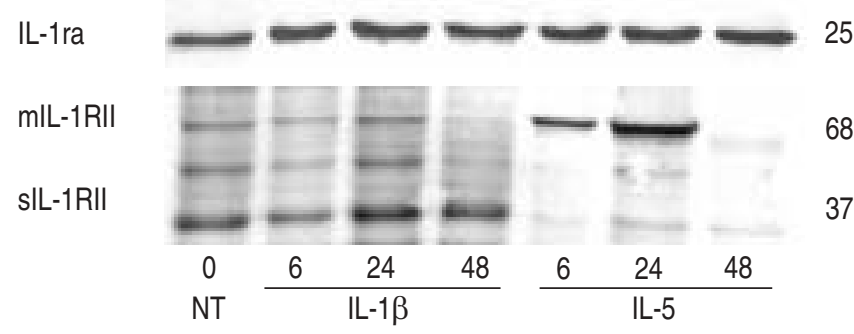

Fig. 6. - Protein expression of inhibitory interleukin (IL)-1 axis molecules in human airway smooth muscle (HASM) cells. Western blots of IL-1 receptor antagonist (IL-1ra) and IL-1 type-II receptor (IL-1RII) protein expression in cultured HASM cells in serum-free medium (SFM) alone (NT) and following 6,24 and $48 \mathrm{~h}$ of treatment with either IL-5 or IL-1 $\beta$. Relative to SFM, IL-1 $\beta$ and IL-5 treated cells exhibited increased protein levels of IL-1ra, and that soluble (s)IL-1RII and membrane (m)IL-1RII expression was also increased following treatment with IL-1 $\beta$ and IL-5. Molecular weight is expressed on the right of the figure $(\mathrm{kDa})$. Experiments were performed in triplicate.

\section{Protein release of the $I L-1$ axis inhibitory molecules $I L$ - Ira and $S I L-1$ RII}

Given the previous results demonstrating induced upregulated expression of the inhibitory IL-1 axis molecules in response to IL-5 and IL-1 $\beta$, protein levels of secreted IL-1ra and sIL-1RII were assayed in parallel in the media of cultured HASM cells that were exposed to IL-5 or IL- $1 \beta$. Compared to control cells, IL-1ra levels were nearly doubled at $24 \mathrm{~h}$ in cells incubated with IL-5 and increased nearly 4 -fold at $24 \mathrm{~h}$ in response to IL-1 $\beta$ (fig. 7a). In contrast, whereas exposure for $24 \mathrm{~h}$ to SFM alone had no effect on sIL-1RII production, cells exposed to IL-5 and IL-1 $\beta$ exhibited a 10- and 20 -fold increase in sIL-1RII protein levels, respectively (fig. 7b).

Finally, to determine whether the sensitising effects of $\operatorname{IgE}$ immune complex in HASM cells are IL-5 dependent, the release of IL-1 $\beta$ in IgE immune cx-treated HASM cells was measured in the absence and presence of an IL-5ra. As shown in figure 8, exposure of HASM cells to IgE immune cxs triggered the release of IL-1 $\beta$ into the culture media, and this release was markedly attenuated in the presence of IL-5ra. These results concur with previous observations by the present authors using atopic asthmatic serum [9].

Taken together, these results provide extended support for the notion that the sequence of events is IgE-triggered release of IL-5 that triggers IL- $1 \beta$, wherein the latter cytokine directly regulates the expression of both inhibitory and stimulatory IL-1 axis molecules.

\section{Discussion}

It has been well established that IL-1 is a critical mediator of the inflammatory process in various disease states, including asthma [10]. The pleiotropic nature of IL-1 $\beta$ results in the activation of a wide range of cells, including cells involved in the pathobiology of asthma, such as mast cells, Tand B-lymphocytes, epithelial cells and airway smooth muscle cells $[6,9]$. Moreover, both human and animal studies have identified IL-1 $\beta$ as one of the key molecules responsible for induction of altered airway responsiveness in experimental asthma according to its direct action on the ASM [6,9]. In this regard, it is worth noting that, apart from its contractile properties, ASM is capable of producing IL-1 $\beta$ as well as a wide range of other inflammatory molecules that have been implicated in asthma $[8,9,26,27]$. A recent study by the current authors also showed that when administered to ASM
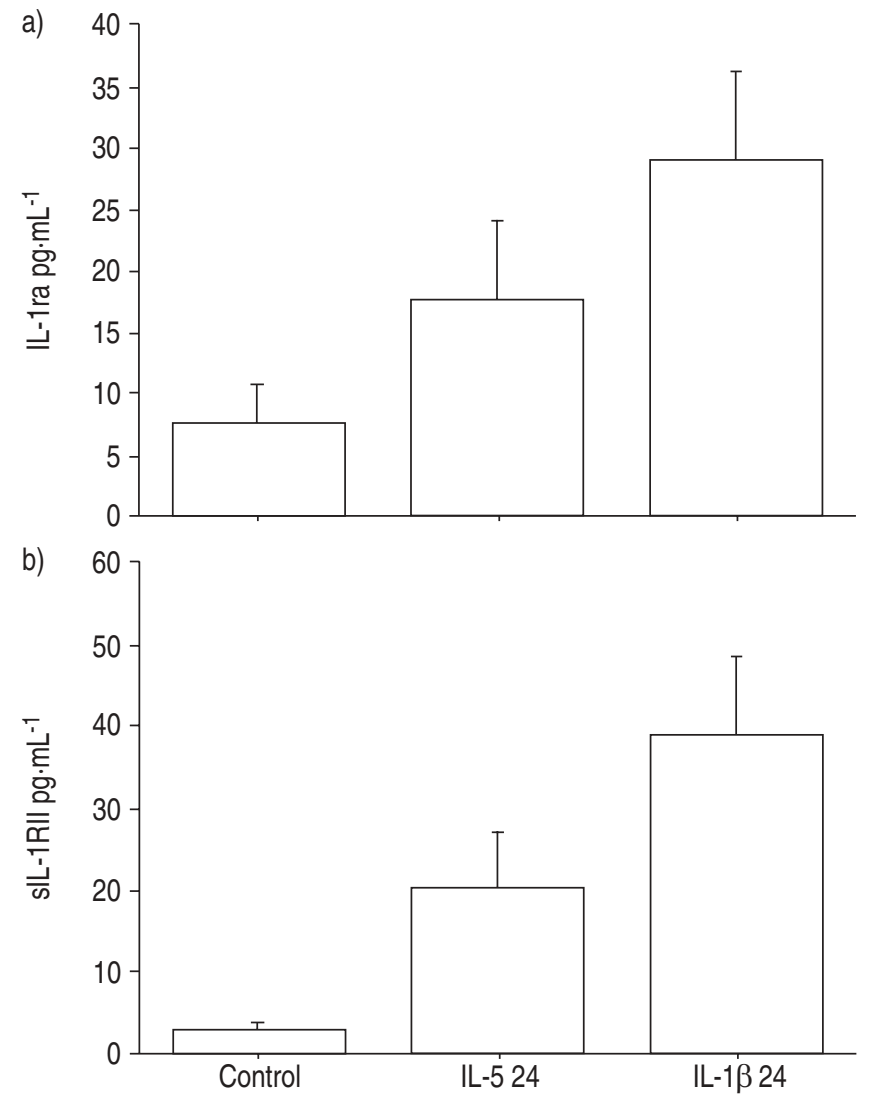

Fig. 7. - Protein release of inhibitory interleukin (IL)-1 axis molecules in human airway smooth muscle (HASM) cell culture media. Comparison of IL-1 receptor antagonist (IL-1ra) and soluble IL-1 type II receptor (sIL-1RII) protein accumulation in the culture media of HASM cells after incubation in serum-free medium alone (control), and following $24 \mathrm{~h}$ exposure to either IL-5 or IL-1 $\beta$ (mean \pm SD). Relative to control values, treatment with both IL-5 and IL-1 $\beta$ resulted in significantly increased release of a) IL-1ra and b) sIL-1RII protein into the cell culture media at $24 \mathrm{~h}$. Experiments were performed in triplicate.

cells, IL-1 $\beta$ is capable of modulating the expression of hundreds of genes, of which a large number have been previously implicated in the pathobiology of asthma [28]. These studies lend further support to the notion that apart from its role in regulation of airway calibre, the ASM also has synthetic functions, producing molecules that are involved in the development of the airway inflammatory response and induction of altered airway responsiveness in asthma.

In light of the evidence implicating a compelling role for IL-1 in asthma, the present study examined the expression, action and regulation of molecules responsible for IL-1 signalling in asthmatic-sensitised ASM. The results demonstrate that: 1) ASM expresses mRNA and protein for both stimulatory and inhibitory IL-1 axis molecules, and the expression of these molecules is modulated in ASM cells in the asthmatic-sensitised state; 2) the endogenously produced inhibitors of IL-1 signalling, IL-1ra and sIL-1RII, attenuate the observed changes in ASM responsiveness following exposure to IL-5, IgE cxs or IL-1 $\beta$; 3) treatment of ASM with IgE cxs, IL-5 and IL-1 $\beta$ induces mRNA expression of IL-1 axis molecules in a time-dependent manner consistent with IgE-triggered release of IL-5, which results in the production of IL-1 $\beta$, and 4) IL-1 axis proteins are expressed by ASM in a manner, consistent with the earlier temporal pattern of mRNA expression.

In this study, the present authors have shown that 


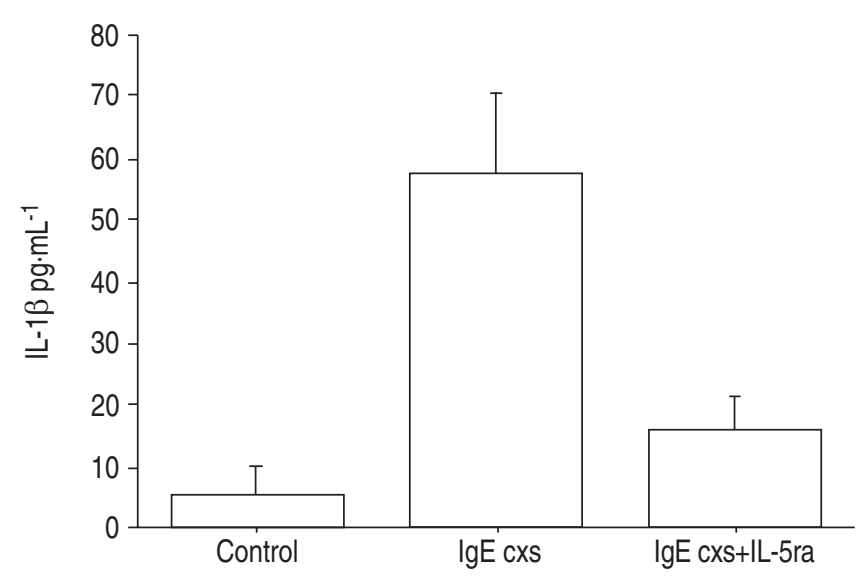

Fig. 8.-Interleukin (IL)-1 $\beta$ release from immunoglobulin (Ig)E immune complex sensitised human airway smooth muscle (HASM) cells. Comparison of IL-1 $\beta$ protein accumulation in the culture media of HASM cells after incubation in serum-free medium alone (control), and following $24 \mathrm{~h}$ treatment with IgE immune complexes (IgE cxs) in the absence and presence of IL-5 receptor antagonist (IL-5ra). Relative to control values, treatment with IgE cxs resulted in significantly increased release of IL-1 $\beta$ protein into the cell culture media at $24 \mathrm{~h}$, and these effects were markedly attenuated in cells that were pre-treated with IL-5ra. Experiments were performed in triplicate.

pre-treatment of ASM with either IL-1ra or sIL-1RII ablates IL-5-induced changes in ASM responsiveness (figs 1 and 2). Comparable results were observed in response to IgE immune cx therapy. These findings are consistent with earlier reports showing that the changes exhibited in airway constrictor and relaxant responsiveness in atopic-asthmatic serum sensitised ASM (i.e. serum containing high levels of $\operatorname{IgE}$ ) were largely ablated by pre-treatment with IL-1ra [9], thereby lending further support to the concept that IgE-induced changes in ASM responsiveness are attributed to the induced release and autocrine action of IL-5 that subsequently triggers the release of IL- $1 \beta$ by the ASM. Given the important role of IL- $1 \beta$ in the development of altered ASM responsiveness and activation of multiple inflammatory pathways in airway cells, the consideration is raised that the expression and action of other IL-1 family molecule members may be involved in the initiation and perpetuation of the pro-asthmatic phenotype, and that perturbation in the expression and regulation of the IL-1 axis molecules may underlie the dysregulated airway inflammatory response in asthma. The presented data suggests that IL-1 $\beta$ and other members of the IL-1 axis of molecules are involved in initiating and propagating the induced changes in airway responsiveness in asthmaticsensitised ASM.

As indicated by the mRNA expression patterns in figure 3, administration of IL-5 induced mRNA expression of all the IL-1 axis molecules within $3 \mathrm{~h}$ of exposure, with the notable exception of: IL- $1 \alpha$, which did not show an altered expression at any time; and IL-1 $\beta$, which exhibited increased expression only at $6 \mathrm{~h}$. Since IL-5 is thought to be critically involved in the inflammatory cascade in asthma, it is of particular interest that IL-5 not only served to induce expression of IL-1 $\beta$, but induced expression of all the other IL-1 family members that have been associated with the IL-1 receptor complex in a time-dependent manner that precedes induction of IL-1 $\beta$ expression itself. The latter observation lends support to the notion that IL-5 may serve to "prime" the ASM for IL-1 signalling and that IL-5 is able to trigger production of the proteins necessary for the IL-1 receptor complex prior to inducing production of IL-1 $\beta$ itself. These interesting new results provide further insight into the regulatory role of IL-5 in the development of pulmonary inflammation and airway hyperresponsiveness exhibited in experimental asthma [23, 29], and show that the effects of IL-5 are largely attributed to its triggering of an orchestrated IL-1 response. This concept concurs with the findings in a previous study showing that airway hyperresponsiveness initiated by IL- 5 is insensitive to subsequent IL-5 blockade [30]. Accordingly, administration of IL-5 to HASM is seen to initially induce the IL-1 receptor complex and IL-1 $\beta$ production, of which both are necessary for altered agonist-mediated airway responsiveness and an amplified inflammatory response. Given this consideration, it follows that IL-5-directed therapeutic intervention administered subsequent to IL-5-mediated activation of the IL-1 axis may be insufficient to reverse IL-1 $\beta$-induced changes in ASM responsiveness, producing little therapeutic benefit on the pro-asthmatic response, consistent with previous studies [30]. Furthermore, it can be postulated that by preventing initial IL-5 action, the resultant IL-1-mediated signalling may be dampened, leading to attenuated expression of the asthmatic phenotype.

As shown in figures 3 and 4, the expression of several of the IL-1 axis genes is increased at $3 \mathrm{~h}$ in response to IgE immune cxs. However, despite the relatively early increase in expression of most of the molecules necessary for IL-1 signalling, one notable exception is IL-1RI, which exhibits no increase in expression until $24 \mathrm{~h}$ following exposure to IgE immune cxs. Since IL-5 protein elaboration can occur as early as $3 \mathrm{~h}$ after administration of IgE immune cxs, it is plausible that the IL-1RI expression seen is secondary to IgE-mediated IL-5 production in ASM and may account for the subsequent IL$1 \mathrm{RI}$ increase at $24 \mathrm{~h}$. Indeed, the latter effects were ablated in the presence of an anti-IL-5 monoclonal antibody (data not shown).

Taken together, the above studies demonstrate that IL-1 $\beta$, IgE immune cxs and IL-5 are capable of inducing the expression and release of a wide range of proteins necessary for IL-1 signalling, and that all of these mediators probably work in a concerted manner to optimise IL-1 signalling in HASM. While the role of these mediators may vary, the above evidence implies that IL-5 is the principal cytokine that generates the IL-1 receptor complex, although the mechanism by which this occurs remains to be elucidated.

Given this proposed role of IL-5 in initiating transcription of the IL-1 receptor complex, it is interesting to note that, among the inhibitory members of the IL-1 family, the membrane-bound form of IL-1RII (mIL-1RII) is the major protein product observed in response to IL-5 administration. It can be postulated that in the presence of IL-5, IL-1 signalling is modulated at the level of the ASM itself. In contrast to IL-5, treatment with IL-1 $\beta$ primarily induces elaboration of IL-1ra and sIL-1RII proteins, as shown by both the Western blot and immunoassay results in figures 6 and 7. sIL-1RII and IL-1ra have been shown to regulate, at least in part, the level of IL- $1 \beta$ in the local environment, by binding the cytokine and its functional receptor, respectively. Since infiltration of inflammatory cells, notably eosinophils, macrophages, mast cells and neutrophils, into the asthmatic airway is known to occur during asthma exacerbation and that these immune cells are exposed to IL-1 $\beta$ in the airway, a counter-regulatory mechanism may exist in these cells that limits an excessive immune response. Based on the preceding evidence, it appears that, in order to prevent an excessive immune response, IL- $1 \beta$-stimulated ASM cells produce IL1ra and sIL-1RII, both of which are soluble proteins that could dampen IL-1 signalling in all cell types participating in the local airway pro-inflammatory response.

When an inflammatory response is triggered in a normal setting, the IL-1 axis molecules, sIL-1RII, IL-1ra and IL-1 $\beta$, 
have been shown to be expressed and released in a synchronised manner that balances the immune response [31]. Recent studies have shown that, in certain disease states, there is an imbalance of production of IL-1 $\beta$ and IL-1 ra. This phenomenon may also occur in the asthmatic-sensitised state [24, 31-33]. Accordingly, imbalance in IL-1 axis molecules with either insufficient levels of either IL-1ra or sIL-1RII and/ or excessive levels of IL-1 $\beta$ could underlie the pro-asthmatic phenotype. Although the roles that IL-5 and IL- $1 \beta$ play in maintaining the proper cytokine/inhibitor balance in the asthmatic airway remain unclear, given the ability of the above mediators to modulate the expression of IL-1 $\beta$ itself and of IL-1ra, and sIL-1RII, and various other molecules, it is reasonable to suggest that these cytokines may, at least in part, be responsible for a dysregulated airway inflammatory response in asthma.

In summary, this study shows that IgE immune cxs, IL-1 $\beta$ and IL-5 regulate the expression and action of multiple molecules associated with the IL-1 receptor complex. Of particular interest is the finding that IL-5 is capable of inducing the production of all of the molecules participating in the IL-1 receptor complex prior to initiation of transcription of IL-1 $\beta$ itself, implicating IL-5 as a mediator that may serve to heighten the ASM response to IL-1 $\beta$. These findings are consistent with the previously described sequential autocrine release of IL-5 and IL-1 $\beta$ in response to ASM sensitisation with atopic asthmatic serum [9]. Since the expression of IL-5 precedes that of IL- $1 \beta$ in the inflammatory cascade, the necessary components for IL-1 signalling are upregulated by the same mediator that induces production of the cytokine itself. Moreover, consistent with the notion that IL-5 may provide an environment initially permissive to IL-1 signalling, a counter-regulatory mechanism may subsequently take place by the induced, upregulated expression and action of mIL-1RII that is aimed at dampening the IL-1 signalling pathway. This would serve to limit IL-1 $\beta$ activation of the ASM without significantly altering the amounts of IL-1 $\beta$ available in the surrounding airway milieu, potentially allowing for paracrine activation of other cells normally involved in the inflammatory response that characterises asthma. In contrast, IL-1 $\beta$-treated ASM produces primarily sIL-1RII and IL-1ra, which act to reduce the amount of IL-1 $\beta$ available to bind to the IL-1RI receptor, a mechanism that would serve to temper the overall immune response and ASM activation.

In light of the collective evidence, the current authors conclude that the IL-1 family of molecules plays an important role in regulating airway smooth muscle responsiveness, as well as their own receptor dynamics, and levels in the local airway milieu. This leaves several interesting therapeutic options at the interleukin-5 and interleukin-1 $\beta$ level in asthma, some of which have been examined previously [34, $35,36]$, but may need to be optimised with respect to airway smooth muscle itself.

Acknowledgements. The authors would like to thank S. Chuang and J. S. Grunstein for their expert technical assistance.

\section{References}

1. Bousquet J, Chanez P, Lacoste JY, et al. Eosinophilic inflammation in asthma. N Engl J Med 1990; 323: 10331039.

2. Goldie RG, Spina D, Henry PJ, Lulich KM, Paterson JW. In vitro responsiveness of human asthmatic bronchus to carbachol, histamine, beta-adrenoceptor agonists and theophylline. Br J Clin Pharmacol 1986; 22: 669-676.
3. Koning H, Neijens HJ, Baert MR, Oranje AP, Savelkoul HF. T cell subsets and cytokines in allergic and non-allergic children. I. Analysis of IL-4, IFN-gamma and IL-13 mRNA expression and protein production. Cytokine 1997; 9: 416-426.

4. Romagnani S. Biology of human TH1 and TH2 cells. J Clin Immunol 1995; 15: 121-129.

5. Shimoda K, van Deursen J, Sangster MY, et al. Lack of IL4-induced Th2 response and IgE class switching in mice with disrupted Stat6 gene. Nature 1996; 380: 630-633.

6. Hakonarson H, Herrick DJ, Serrano PG, Grunstein MM. Autocrine role of interleukin 1beta in altered responsiveness of atopic asthmatic sensitised airway smooth muscle. J Clin Invest 1997; 99: 117-124.

7. Hakonarson $\mathrm{H}$, Whelan $\mathrm{R}$, Leiter $\mathrm{J}$, et al. $\mathrm{T}$ lymphocytemediated changes in airway smooth muscle responsiveness are attributed to induced autocrine release and actions of IL5 and IL-1beta. J Allergy Clin Immunol 2002; 110: 624-633.

8. Shore SA, Moore PE. Effects of cytokines on contractile and dilator responses of airway smooth muscle. Clin Exp Pharmacol Physiol 2002; 29: 859-866.

9. Hakonarson H, Maskeri N, Carter C, Chuang S, Grunstein MM. Autocrine interaction between IL-5 and IL-1beta mediates altered responsiveness of atopic asthmatic sensitized airway smooth muscle. J Clin Invest 1999; 104: 657-667.

10. Dinarello CA. Interleukin-1, interleukin-1 receptors and interleukin-1 receptor antagonist. Int Rev Immunol 1998; 16: 457-499.

11. Borish L, Mascali JJ, Dishuck J, Beam WR, Martin RJ, Rosenwasser LJ. Detection of alveolar macrophage-derived IL-1 beta in asthma. Inhibition with corticosteroids. J Immunol 1992; 149: 3078-3082.

12. Pujol JL, Cosso B, Daures JP, Clot J, Michel FB, Godard P. Interleukin-1 release by alveolar macrophages in asthmatic patients and healthy subjects. Int Arch Allergy Appl Immunol 1990; 91: 207-210.

13. Kuno K, Matsushima K. The IL-1 receptor signaling pathway. J Leukoc Biol 1994; 56: 542-547.

14. Greenfeder SA, Nunes P, Kwee L, Labow M, Chizzonite $\mathrm{RA}, \mathrm{Ju}$ G. Molecular cloning and characterization of a second subunit of the interleukin 1 receptor complex. $J$ Biol Chem 1995; 270: 13757-13765.

15. Huang J, Gao X, Li S, Cao Z. Recruitment of IRAK to the interleukin 1 receptor complex requires interleukin 1 receptor accessory protein. Proc Natl Acad Sci USA 1997; 94: 1282912832.

16. Colotta F, Dower SK, Sims JE, Mantovani A. The type II 'decoy' receptor: a novel regulatory pathway for interleukin 1. Immunol Today 1994; 15: 562-566.

17. Symons JA, Young PR, Duff GW. Soluble type II interleukin 1 (IL-1) receptor binds and blocks processing of IL-1 beta precursor and loses affinity for IL-1 receptor antagonist. Proc Natl Acad Sci USA 1995; 92: 1714-1718.

18. Dripps DJ, Brandhuber BJ, Thompson RC, Eisenberg SP. Interleukin-1 (IL-1) receptor antagonist binds to the $80-\mathrm{kDa}$ IL-1 receptor but does not initiate IL-1 signal transduction. J Biol Chem 1991; 266: 10331-10336.

19. Ohlsson K, Bjork P, Bergenfeldt M, Hageman R, Thompson RC. Interleukin-1 receptor antagonist reduces mortality from endotoxin shock. Nature 1990; 348: 550-552.

20. Saperas E, Tache Y. Central interleukin-1 beta-induced inhibition of acid secretion in rats: specificity of action. Life Sci 1993; 52: 785-792.

21. Oshikawa K, Kuroiwa K, Tago K, et al. Elevated soluble ST2 protein levels in sera of patients with asthma with an acute exacerbation. Am J Respir Crit Care Med 2001; 164 : 277-281.

22. Hakonarson H, Maskeri N, Carter C, Grunstein MM. Regulation of TH1- and TH2-type cytokine expression and action in atopic asthmatic sensitized airway smooth muscle. J Clin Invest 1999; 103: 1077-1087.

23. Hakonarson H, Carter C, Kim C, Grunstein MM. Altered expression and action of the low-affinity $\operatorname{IgE}$ receptor 
FcepsilonRII (CD23) in asthmatic airway smooth muscle. J Allergy Clin Immunol 1999; 104: 575-584.

24. Foster PS, Hogan SP, Ramsay AJ, Matthaei KI, Young IG. Interleukin 5 deficiency abolishes eosinophilia, airways hyperreactivity, and lung damage in a mouse asthma model. J Exp Med 1996; 183: 195-201.

25. Jablonska E, Jablonski J, Piotrowski L, Grabowska Z. IL1beta, IL-1Ra and sIL-1RII in the culture supernatants of PMN and PBMC and the serum levels in patients with inflammation and patients with cancer disease of the same location. Immunobiology 2001; 204: 508-516.

26. Amrani Y, Panettieri RA Jr. Cytokines induce airway smooth muscle cell hyperresponsiveness to contractile agonists. Thorax 1998; 53: 713-716.

27. Hakonarson H, Herrick DJ, Grunstein MM. Mechanism of impaired beta-adrenoceptor responsiveness in atopic sensitized airway smooth muscle. Am J Physiol 1995; 269: L645L652.

28. Hakonarson H, Halapi E, Whelan R, Gulcher J, Stefansson $\mathrm{K}$, Grunstein MM. Association between IL-1beta/TNFalpha-induced glucocorticoid-sensitive changes in multiple gene expression and altered responsiveness in airway smooth muscle. Am J Respir Cell Mol Biol 2001; 25: 761-771.

29. Nag SS, Xu LJ, Hamid Q, Renzi PM. The effects of IL-5 on airway physiology and inflammation in rats. $J$ Allergy Clin Immunol 2003; 111: 558-566.

30. Mathur M, Herrmann K, Li X, et al. TRFK-5 reverses established airway eosinophilia but not established hyperresponsiveness in a murine model of chronic asthma. Am J Respir Crit Care Med 1999; 159: 580-587.

31. Kline JN, Fisher PA, Monick MM, Hunninghake GW. Regulation of interleukin-1 receptor antagonist by Th1 and Th2 cytokines. Am J Physiol 1995; 269: L92-L98.

32. Gupta K, Bewtra A. IL-1 receptor-type expression in relation to atopy. J Allergy Clin Immunol 1999; 103: 1100-1107.

33. Mao XQ, Kawai $\mathrm{M}$, Yamashita $\mathrm{T}$, et al. Imbalance production between interleukin-1beta (IL-1beta) and IL-1 receptor antagonist (IL-1Ra) in bronchial asthma. Biochem Biophys Res Commun 2000; 276: 607-612.

34. Fanslow WC, Sims JE, Sassenfeld H, et al. Regulation of alloreactivity in vivo by a soluble form of the interleukin-1 receptor. Science 1990; 248: 739-742.

35. Fernandez-Botran R. Soluble cytokine receptors: novel immunotherapeutic agents. Expert Opin Investig Drugs 2000; 9: 497-514.

36. Weckmann AL, Alcocer-Varela J. Cytokine inhibitors in autoimmune disease. Semin Arthritis Rheum 1996; 26: 539557. 